\title{
Synthesis and Evaluation of Biocide and Cetane Number Improver Additives for Biodiesel from Chemical Changes in Triacylglycerides
}

\author{
Kênia P. Costa, ${ }^{a}$ Stella F. do Valle, ${ }^{a}$ Thayana F. L. dos Santos, ${ }^{b}$ Ellen T. Rangel, ${ }^{b}$ \\ Angelo C. Pinto, ${ }^{a, \dagger}$ Paulo A. Z. Suarez ${ }^{b}$ and Michelle J. C. Rezende ${ }^{*, a}$ \\ aInstituto de Química, Universidade Federal do Rio de Janeiro, \\ Cidade Universitária, CT, Bloco A, 21941-909 Rio de Janeiro-RJ, Brazil \\ ${ }^{b}$ Laboratório de Materiais e Combustíveis, Instituto de Química, \\ Universidade de Brasília, 70910-970 Brasília-DF, Brazil
}

\begin{abstract}
Biodiesel demand is increasing all over the world and the inhibition of microbial growth during the storage of this biofuel is extremely important. There are few studies involving the evaluation of biocides specifically for biodiesel. In the present work, we synthesized and evaluated a set of biocide candidates from chemical transformations in triacylglycerides. Samples of pure biodiesel with the products were evaluated against microorganisms which have been isolated from biodiesel/diesel blends (fungi A. niger, A. fumigatus, C. albicans and S. cerevisiae; and bacteria B. subtilis and Acinetobacter sp.). None of the products inhibited the growth of bacteria. Four nitrated derivatives presented fungicidal activity. The nitrated derivatives were also evaluated as cetane number improvers for B7 biodiesel/diesel blend. The nitrates of soybean methoxylated ethylene glycol esters increased the cetane number by more than three points. Despite showing modest biocide activity, the results can guide the planning of new products from triacylglycerides.
\end{abstract}

Keywords: additives, antimicrobial activity, biodeterioration, biodiesel, cetane number

\section{Introduction}

Renewable fuels, such as biodiesel and bioethanol, have been pointed out as an elegant solution for the increasing demand on liquid fuels and address also the increasing global warming awareness. For instance, biodiesel has been used pure or blended to diesel in compression ignition engines by many countries. Some advantages of its use include the equalized balance of $\mathrm{CO}_{x}$ emission, the absence of sulfur compounds and the effective reduction of greenhouse gas emission. ${ }^{1}$ However, the only concern regarding the use of biodiesel is the increasing in $\mathrm{NO}_{x}$ emissions. Note that biodiesel, which is a mixture of methyl or ethyl fatty acid esters, does not have nitrogen in its composition and, thus, the increasing $\mathrm{NO}_{\mathrm{x}}$ emissions is not due to enhancing nitrogen content in the fuel, but because of the augmenting temperature in the burning chamber of the engine, as pointed out in the literature (see, for instance, Carvalho Jr. and Lacava). ${ }^{2}$

*e-mail: mjcrezende@gmail.com

This paper is dedicated to the memory of professor Angelo da Cunha Pinto, who recently passed away.
In 2005, Brazil introduced biodiesel in its energy market and the mandatory addition of this biofuel in diesel has been increasing gradually over the years. ${ }^{3}$ Since March 2018, diesel available at fuel stations has mandatory addition of $10 \%$ biodiesel (B10). In Brazil, the main industrial production of biodiesel is performed by methanolysis of triacylglycerides, using mainly hydroxide or alkoxide as catalyst. ${ }^{4}$ It is worth to mention that the demand for this biofuel in Brazil has increased not only because of the gradually augmenting of blending, but also due to the growing diesel consumption.

Nonetheless, when the use of B5 (diesel with addition of $5 \%$ biodiesel) became mandatory several issues regarding slime formation in fuel tanks were observed during storage and the main reasons pointed out were chemical and microbial biodiesel degradation. ${ }^{5}$ The accumulation of organic material due to fuel chemical or biological degradation leads to systemic problems in engines, such as clogging of filters, damage to the injection system and a significant reduction of fuel quality. ${ }^{6-8}$

Regarding fuel degradation, it is worth to mention that it occurs in various fuel systems, and it is closely linked to 
the proliferation of microbes, especially fungi and bacteria, that are capable of metabolizing hydrocarbons, using them as source of energy. ${ }^{9}$ The growth of microorganisms not only forms slime, but also affects several properties of the fuel, primarily through the production of metabolites capable of accelerating its deterioration, ${ }^{9-11}$ affecting the performance of the fuel and also damaging the structure of storage tanks. The renovation of biodiesel in the storage tank is crucial to control the problem because the longer the storage time, the greater the probability of microbial contamination. The two main types of damage caused by microbes are microbiologically induced corrosion and fouling. The last one develops a biofilm on the surface of fuel systems. The accumulation of the biofilm causes decrease of pipe diameter leading to flow restriction and can also interfere in the real measure of the amount of fuel in the tank. ${ }^{11}$

The problem of microbial contamination in fuels can be prevented or remediated. The prevention strategy includes the removal of the water from the system and the monitoring of the whole process of biodiesel production in order to avoid contamination at all levels. It is well known that water is an essential factor for microbial growth. The control of the presence of water in fuel systems is an alternative procedure to avoid microbial contamination, but it is not an easy task. Specifically for biodiesel, which has a higher hygroscopicity compared to other fuels based on hydrocarbons, it is even more difficult to keep low water content. ${ }^{12}$ The remediation strategy is divided in physical or chemical remediation. The physical methods consist of sedimentation, filtration and heat treatment, but none of these is effective in eliminating the deposition of organic matter on the bottom of the tanks. ${ }^{11}$ The chemical remediation is the treatment with biocide. There are three approved and registered biocides by U.S. EPA for use in diesel. ${ }^{11}$ The first additive (DOB) is composed by 2,2-oxybis(4,4,6-trimethyl-1,3,2-dioxaborinane) and 2,2-(1-methyltrimethylenedioxy)-bis-(4-methyl-1,3,2-dioxaborinane). The second biocide formulation (CMIT/MIT) consists of 5-chloro-2-methyl-4-isothiazolin-3-one and 2-methyl4-isothiazolin-3-one. And the third additive (NBM/ENDM) is a mixture of 4-(2-nitrobutyl)morpholine and 4,4'-(2-ethylnitrotrimethylene)dimorpholine. There is also a fourth product that is used for fuels microbicidal treatment known as MBO [3,3'-methylenebis(5-methyloxazolidine)]. CMIT/MIT and MBO were evaluated in biodiesel and biodiesel/diesel blends by Zimmer et al. ${ }^{8}$ and Bücker et al. ${ }^{13}$ $\mathrm{NBM} / \mathrm{ENDM}$ was tested as fungicide in biodiesel samples from different raw materials by Cazarolli et al. ${ }^{14}$ Recently, Zimmer et al ${ }^{15}$ published the results of the use of MBO as biocide under simulated storage conditions. MBO was added in B10 biodiesel/diesel blend for controlling microbial contamination under two conditions: at lab-scale and in the field (real-world condition).${ }^{15}$ Despite the knowledge of these biocides, these additives are not used in Brazilian commercial biodiesel, mainly because some are borate compounds, which are responsible for generating particulate materials, and others contain sulfur in its composition, and by Brazilian fuel standards ${ }^{16}$ the maximum sulfur allowed in diesel is $10 \mathrm{ppm}$, making it unfeasible to use as an additive. In addition, Brazil does not have a specific legislation for biocides. This scenario leaves us at a disadvantage compared to other countries that carry out a strict regulatory control, production and commercialization of this type of product.

Cetane number $(\mathrm{CN})$ is a measure of the ignition quality of diesel fuel in a compression ignition engine. ${ }^{17}$ The shorter the ignition delay (the time between the start of injection and the start of combustion) the better will be the fuel ignition quality. ${ }^{18} \mathrm{In}$ Brazil, the $\mathrm{CN}$ limit is regulated by the Brazilian National Agency of Petroleum, Natural Gas and Biofuels (ANP) in the Resolution ANP 30 of June, 2016. ${ }^{16}$ The minimum CN limit for diesel S-10 is 48. A long ignition delay $(\mathrm{CN}<48)$ causes accumulation of unburned fuel in the chamber. Studies have shown that increasing the cetane number of the fuel significantly improves fuel combustion, reducing particulate matter and gaseous emissions. ${ }^{19-22}$ On the other hand, some reports show that an immediate burning of fuels with $\mathrm{CN}$ higher than 60 causes damage to the engine such as the power reduction and fatigue of the mechanical components. ${ }^{23}$

The increase in cetane number by additives is a valuable means of improving diesel fuel quality. ${ }^{24,25}$ Addition of $0.1-0.25 \%$ of $\mathrm{CN}$ improvers will typically increase the cetane number of diesel fuels by an average of six cetane numbers. ${ }^{26}$ Suitable additives are, for example, alkyl nitrates, ether nitrates, alkyldiglycol nitrates, and organic peroxides. ${ }^{27}$ Indeed, nitrates have been the class of compounds responsible for the cetane number improvement. The predominant commercial cetane improver is 2-ethylhexyl nitrate since it is the most popular and cost-effective.

As far as our knowledge, there is only one work reporting the synthesis and evaluation of antimicrobial additives candidates for biodiesel in the literature. ${ }^{28}$ Regarding to cetane number improvers, Suppes et al. ${ }^{29-31}$ published a sequence of three studies. The first involved the synthesis of fatty acid glycol nitrates, ${ }^{29}$ followed by the synthesis of dinitrate of oleic acid methyl ester ${ }^{30}$ and alkyl nitrate derivatives of soybean, castor, olive and canola oils. ${ }^{31}$ In 2007, Canoira et al. ${ }^{32}$ synthesized nitro and nitrate derivatives directly from biodiesel of waste frying oil. The 
addition of nitrated biodiesel in diesel increased the cetane number of the fuel by more than five points.

The main purpose of this study is the synthesis and evaluation of a set of biocide candidates for use as additive in pure biodiesel. Nitro compounds are known to have bactericidal and fungicidal activity. In this work, the goal is the evaluation of nitrated derivatives from triacylglycerides, the same raw material used for biodiesel production, using simple and low cost chemical transformations. The biocide action of intermediate synthetic products is also being investigated. The nitrated products, specifically, are also evaluated as cetane number improver additives for biodiesel/diesel blend.

\section{Experimental}

Transesterification of vegetable oils with ethylene glycol

The 2-hydroxyethyl esters were obtained from the reaction of vegetable oil (about $21 \mathrm{~g}$ of soybean, jatropha or castor oil) with ethylene glycol (18 g) in a triacylglyceride/ alcohol molar ratio of $1: 12$ using $9 \mathrm{~mol} \%$ of anhydrous potassium carbonate $(0.3 \mathrm{~g})$ as catalyst. The round-bottom flask $(125 \mathrm{~mL})$ was connected to a reflux condenser and immersed in a heating bath at $170-175^{\circ} \mathrm{C}$ for $90 \mathrm{~min}$. The reaction medium was kept under constant magnetic stirring at atmospheric pressure. After the reaction, the mixture was cooled and poured into $100 \mathrm{~mL}$ of ethyl acetate. The organic layer was washed with distilled water $(3 \times 30 \mathrm{~mL})$ and then dried over anhydrous sodium sulfate. The solvent was removed by evaporation under reduced pressure.

\section{Transesterification of soybean oil with glycerol}

In a Parr reactor $(100 \mathrm{~mL})$, the vegetable oil $(50 \mathrm{~g})$ and the dibutyltin IV oxide $(0.5 \mathrm{~g})$ catalyst were added in the mass ratio of 100:1 with 2 equiv. of glycerol (10.5 g). The reaction mixture was then submitted to vigorous magnetic stirring at $200{ }^{\circ} \mathrm{C}$ for $2 \mathrm{~h}$. The resulting off-white material was stored in a freezer in order to prevent degradation or oxidation.

\section{Esterification of fatty acid with ethylene glycol}

In a round bottom flask, fatty acid (about $10 \mathrm{~g}$ of linoleic acid, oleic acid or stearic acid) and ethylene glycol (8.7 g) were added in a fatty acid/alcohol molar ratio of 1:4 using $2 \% \mathrm{~m} / \mathrm{m}$ of sulfuric acid $(0.11 \mathrm{~mL})$ as catalyst. The mixture was kept under magnetic stirring at $170{ }^{\circ} \mathrm{C}$ for $3 \mathrm{~h}$. After the reaction, the mixture was cooled and neutralized with saturated sodium bicarbonate solution. $50 \mathrm{~mL}$ of ethyl acetate was added and the organic layer was washed with distilled water. Then, it was dried over anhydrous sodium sulfate and the solvent was removed by evaporation under reduced pressure.

\section{General procedure for epoxidation}

1 equiv. $(5 \mathrm{~g})$ of ester and 2.5 equiv. $(1.7 \mathrm{~mL})$ of formic acid ( $88 \%$ in water solution) were added in a round bottom flask (50 mL). 2.5 equiv. of $50 \%$ hydrogen peroxide $(2.2 \mathrm{~mL})$ was slowly added to the mixture under magnetic stirring at room temperature during $1 \mathrm{~h}$. Then, the mixture was maintained at $70{ }^{\circ} \mathrm{C}$ for $6 \mathrm{~h}$. After the reaction, the mixture was poured into $75 \mathrm{~mL}$ of dichloromethane and washed with $25 \mathrm{~mL}$ of distilled water. The organic layer was dried over anhydrous sodium sulfate and the solvent was removed by evaporation under reduced pressure.

\section{General procedure for hydrolysis}

In a round bottom flask $(250 \mathrm{~mL}), 1$ equiv. of epoxide $(15 \mathrm{~g}), 20$ equiv. of distilled water $(15.3 \mathrm{~mL}), 0.05$ equiv. of concentrated sulfuric acid $(0.1 \mathrm{~mL})$ and 20 equiv. of dioxane $(72 \mathrm{~mL})$ were added. The mixture was kept under magnetic stirring at $90{ }^{\circ} \mathrm{C}$ for $4 \mathrm{~h}$. At the end of reaction, the mixture was poured into $50 \mathrm{~mL}$ of dichloromethane and washed with sodium bicarbonate solution $(1 \times 50 \mathrm{~mL})$ and distilled water $(3 \times 50 \mathrm{~mL})$. The organic layer was dried with anhydrous sodium sulfate and the solvent removed at reduced pressure.

\section{General procedure for solvolysis}

In a round bottom flask $(250 \mathrm{~mL}), 1$ equiv. of epoxide $(11 \mathrm{~g})$ and 97 equiv. of methanol $(120 \mathrm{~mL})$ were added. Under magnetic stirring at room temperature was then added 0.5 equiv. of concentrated sulfuric acid $(0.9 \mathrm{~mL})$. The mixture was kept at $70{ }^{\circ} \mathrm{C}$ and stirred for $12 \mathrm{~h}$. At the end of the reaction, methanol was removed from the flask under reduced pressure. Then the mixture was poured into $50 \mathrm{~mL}$ of dichloromethane and washed with saturated sodium bicarbonate $(4 \times 25 \mathrm{~mL})$ and saturated sodium chloride $(4 \times 25 \mathrm{~mL})$. The organic phase was dried with anhydrous sodium sulfate and the solvent removed at reduced pressure.

\section{General procedure for nitration}

In a round bottom flask, 1 equiv. of hydroxy compound $(4 \mathrm{~g})$ and $8 \mathrm{~mL}$ of dry dichloromethane were added. Then, the mixture was immersed in an ice bath under magnetic stirring and it was slowly added 2.3 equiv. of acetic 
anhydride $(2.2 \mathrm{~mL})$ and 2.2 equiv. nitric acid $(1.5 \mathrm{~mL})$. The system was maintained under these conditions for $5 \mathrm{~h}$. At the end of reaction, the mixture was poured into $75 \mathrm{~mL}$ of dichloromethane and washed with distilled water $(4 \times 50 \mathrm{~mL})$, saturated sodium bicarbonate $(1 \times 50 \mathrm{~mL})$ and again with distilled water $(1 \times 50 \mathrm{~mL})$. The organic layer was dried with anhydrous sodium sulfate and the solvent removed at reduced pressure.

\section{Characterization of the synthesized products}

${ }^{1} \mathrm{H}$ and ${ }^{13} \mathrm{C}$ nuclear magnetic resonance (NMR) spectroscopic measurements were carried out at $298 \mathrm{~K}$ using a Bruker DPX-200 spectrometer. The sample was prepared by dissolving the sample in $0.6 \mathrm{~mL} \mathrm{CDCl}_{3}$. The spectra were referenced to TMS.

Infrared (IR) spectra ( $\mathrm{KBr}$ pellets) were obtained on a spectrometer with Fourier transform (FTIR) from Thermo Scientific model Nicolet 6700, with a wave number range from 400 to $4000 \mathrm{~cm}^{-1}$, a resolution of $4 \mathrm{~cm}^{-1}$ and each spectrum was obtained from the average of 16 scans.

\section{Determination of fatty acid composition of the vegetable oils}

The conversion of triacylglycerides to fatty acid methyl esters was carried out by the transesterification of vegetable oil (soybean, jatropha or castor oil) with methanol in a triacylglyceride/alcohol molar ratio of 1:9 using $3 \mathrm{~mol} \%$ of anhydrous potassium carbonate as catalyst. The roundbottom flask was connected to a reflux condenser and immersed in a heating bath at $90{ }^{\circ} \mathrm{C}$ for $120 \mathrm{~min}$. The reactional media was kept under constant magnetic stirring at atmospheric pressure. After the reaction, the mixture was cooled and poured into ethyl acetate. The organic layer was washed with distilled water and then dried over anhydrous sodium sulfate. The solvent was removed by evaporation under reduced pressure. The conversion rate (> 90\% for all vegetable oils) was determined by ${ }^{1} \mathrm{H}$ NMR method as described by Gelbard et $_{\text {al. }}{ }^{33}$

Gas chromatography-mass spectrometry (GC-MS) analyzes were performed on a Shimadzu GC-QP2010 gas chromatograph coupled to a Shimadzu GCMS-QP2010 mass spectrometer. Electron ionization at $70 \mathrm{eV}$ ionization energy was used. An RXi-1MS (100\% methylpolysiloxane) capillary column with $30 \mathrm{~m}, 0.25 \mathrm{~mm}$ i.d., and $0.25 \mu \mathrm{m}$ df was used. The carrier gas was helium at a flow rate of $2.0 \mathrm{~mL} \mathrm{~min}{ }^{-1}$. The temperature program was $100{ }^{\circ} \mathrm{C}$, at $5^{\circ} \mathrm{C} \mathrm{min}^{-1}$ to $140^{\circ} \mathrm{C}$ with an isothermal period of $5 \mathrm{~min}$, then at $5{ }^{\circ} \mathrm{C} \mathrm{min}{ }^{-1}$ to $200{ }^{\circ} \mathrm{C}$, followed by $15{ }^{\circ} \mathrm{C} \mathrm{min}{ }^{-1}$ to $280^{\circ} \mathrm{C}$. Injection volume was $1.0 \mu \mathrm{L}$ in split mode and with 1:20 split ratio. The injector temperature was $290{ }^{\circ} \mathrm{C}$. The transfer line and ion source were held at 290 and $250^{\circ} \mathrm{C}$, respectively. SCAN mode was used in the mass range of 40-500 u. The samples for analyses were prepared by dissolving $5 \mathrm{mg}$ of vegetable oil methyl esters in $10 \mathrm{~mL}$ of ethyl acetate. Table 1 presents the fatty acid composition of the vegetable oils.

\section{Agar diffusion antimicrobial test}

The agar diffusion test consists in depositing the product to be tested in a reservoir (hole) made in a Petri dish containing a culture medium. During incubation, the product diffuses from the holes to the culture medium. After incubation, the diameter of the inhibited area (no microorganism growth) was measured. The colonies that grew on the inhibition zone were considered resistant. ${ }^{34}$

The diameter of the inhibited area was measured after $48 \mathrm{~h}$ of incubation at $32-37^{\circ} \mathrm{C}$ using an optical projector, ruler or caliper. The tests were carried out in triplicate on Sabouraud dextrose agar and nutrient agar culture. Common environment microorganisms, which have been isolated from biodiesel/diesel blends, were tested. American type culture collection (ATCC) standard strains of bacteria and fungi were used (fungi Aspergillus niger (INCQS 40067 ATCC 10535), Aspergillus fumigatus (INCQS 40152 ATCC 46640), Candida albicans (INCQS 40178 ATCC 6019) and Saccharomyces cerevisiae (INCQS 40001 ATCC 2601); and bacteria Bacillus subtilis (INCQS 00002 ATCC 19659) and Acinetobacter baumannii (INCQS 00143 ATCC 19606)). ${ }^{35,36}$ Biodiesel and dimethyl sulfoxide (DMSO) were used as negative controls. Positive controls were not used in the tests, since in Brazil there is no antimicrobial additive commercially used in biodiesel.

Table 1. Fatty acid composition of the vegetable oils

\begin{tabular}{lccccccc}
\hline \multirow{2}{*}{ Vegetable oil } & \multicolumn{7}{c}{ Fatty acid composition /\% } \\
\cline { 2 - 7 } & $\mathrm{C} 16: 0$ & $\mathrm{C} 18: 0$ & $\mathrm{C} 18: 1$ & $\mathrm{C} 18: 2$ & $\mathrm{C} 18: 3$ & $\mathrm{C} 18: 1(\mathrm{OH})$ & Others \\
\hline Soybean & 11.6 & 4.1 & 22.1 & 58.5 & 2.5 & - & - \\
Jatropha & 10.5 & 7.1 & 50.9 & 31.5 & - & - & - \\
Castor & 0.6 & 0.9 & 3.0 & 4.3 & - & 89.2 & 2.0 \\
\hline
\end{tabular}

C16:0: palmitic acid; C18:0: stearic acid; C18:1: oleic acid; C18:2: linoleic acid; C18:3: linolenic acid; C18:1(OH): ricinoleic acid. 


\section{Antimicrobial susceptibility test}

The susceptibility of the microorganisms to the synthesized products was evaluated through the microdilution tests with standard Clinical and Laboratory Standards Institute broth. ${ }^{37}$ The concentrations of the products in the microdilution tests varied from 1 to $512 \mu \mathrm{g} \mathrm{mL}^{-1}$. Due to the relatively high viscosity of soybean biodiesel, the samples were previously solubilized in DMSO. DMSO is the most commonly used solvent for dilution of substances to be tested, and it is proven to be non-toxic. ${ }^{38,39}$ The microorganisms studied in this test were the same studied in the agar diffusion test. The culture medium was Roswell Park Memorial Institute (RPMI) 1640 with L-glutamine without sodium bicarbonate, buffered with $0.165 \mathrm{~mol} \mathrm{~L}^{-1}$ 4-morpholinepropanesulfonic acid buffer (MOPS) to $\mathrm{pH} 7.0$, and sterilized. ${ }^{40}$

The inoculum was prepared from yeast colonies grown on Sabouraud dextrose agar for $48 \mathrm{~h}$ at $35^{\circ} \mathrm{C}$. Slurry was prepared in $\mathrm{NaCl} 0.85 \%$ aqueous solution, sterilized, and the cell density measured by spectrophotometer at a transmittance of $85 \%$ at a wavelength of $530 \mathrm{~nm}$. This suspension was subsequently diluted 1:100 and then 1:20 in RPMI 1640 culture medium to achieve a final inoculum concentration of 0.5 to $2.5 \times 10^{3}$ cells $\mathrm{mL}^{-1}$.

For filamentous fungi, the inoculum was prepared from mycelium grown in cultures derived from potato dextrose agar for five days at $35^{\circ} \mathrm{C}$. A suspension was prepared with spores of fungi in sterile $\mathrm{NaCl}$ $0.85 \%$ solution and the cell density was measured by spectrophotometer at a transmittance of $85 \%$ for a wavelength of $530 \mathrm{~nm}$. This suspension was then diluted in RPMI 1640 medium at a ratio of 1:5 affording 0.4 to $5.0 \times 10^{4}$ colony forming units $(\mathrm{CFU}) \mathrm{mL}^{-1}$.

The bacterial inoculum was prepared from the colonies of bacteria grown on nutrient agar. After incubated at $35^{\circ} \mathrm{C}$ for $24 \mathrm{~h}$, the colonies were selected and isolated with a bacteriological loop and transferred to a tube containing $\mathrm{NaCl} 0.85 \%$ aqueous solution. The bacterial suspension was then compared with the standard $0.5 \mathrm{McFarland}$ scale $\left(1.5 \times 10^{8} \mathrm{CFU} \mathrm{mL}^{-1}\right)$. The tube was shaken immediately prior to use. The next step was to add $100 \mu \mathrm{L}$ of the inoculum to each tube containing the test sample already diluted on the plate. The plates were incubated at $35^{\circ} \mathrm{C}$ for $48 \mathrm{~h}, 72 \mathrm{~h}$ and up to 5 days for the tests with bacteria, yeasts and filamentous fungi, respectively. The readings were performed by viewing the turbidity in the culture medium. All tests were performed in triplicate. A control test was done using a blank solution of biodiesel in DMSO, without additive. The lowest concentration of the tested samples that prevented growth represented the minimal inhibitory concentration (MIC).

\section{Cetane number test}

The ignition quality of fuels was evaluated in an IQT-LM (Ignition Quality Tester-Laboratory Model) from Advanced Engine Technology Ltd., according to ASTM D6890 standard method..$^{41}$

\section{Results and Discussion}

Synthesis and spectroscopic characterization of the products

Figure 1 shows the synthetic route to obtain the products using linoleic chain of triacylglycerides for illustration. Note that soybean oil is a mixture of different fatty acids.

${ }^{1} \mathrm{H}$ NMR spectrum of the product of soybean oil transesterification (1) showed characteristic signals between 3.74 and $4.27 \mathrm{ppm}$. These signals correspond to hydrogens 1' and 2' of ethylenic chain, and they are not observed at soybean oil ${ }^{1} \mathrm{H}$ NMR spectrum. ${ }^{13} \mathrm{C}$ NMR spectrum showed signals at 61.48 and $66.09 \mathrm{ppm}$ that correspond to the carbons 1' and 2' of the ethylenic chain. There are no signals in this region of the soybean oil ${ }^{13} \mathrm{C}$ NMR spectrum. In addition to signals concerning the ethylenic portion, signals at 5.34 ppm were observed regarding to the hydrogens bonded to carbons of the double bonds present in the hydrocarbon chains of triacylglycerides. The yield of this reaction was $82 \%$. The infrared spectrum of the product from the transesterification of soybean oil with ethylene glycol (1) shows a large absorption band in $3467 \mathrm{~cm}^{-1}$ related to terminal $\mathrm{O}-\mathrm{H}$ bond of the 2-hydroxyethylesters. An absorption band at $3009 \mathrm{~cm}^{-1}$ corresponds to olefin $\mathrm{C}-\mathrm{H}$ bond and the intense absorption band at $1741 \mathrm{~cm}^{-1}$ corresponds to the axial deformation of the $\mathrm{C}=\mathrm{O}$ bond of the esters.

The reaction of soybean ethylene glycol esters (1) with performic acid generated in situ, at $70{ }^{\circ} \mathrm{C}$ for $6 \mathrm{~h}$, led to complete consumption of double bonds. The mixture of epoxides (2) was confirmed by the absence of the signals in the region of 5.0-5.5 and 120-130 ppm, in ${ }^{1} \mathrm{H}$ and ${ }^{13} \mathrm{C}$ NMR spectra, respectively, related to hydrogens and carbons of the double bonds. The presence of a signal at $53.4 \mathrm{ppm}$ in ${ }^{13} \mathrm{C}$ NMR spectrum corresponds to the oxirane ring carbons. Infrared spectrum did not present the band in the region $3000 \mathrm{~cm}^{-1}$, characteristic of the axial deformation of the $\mathrm{C}-\mathrm{H}$ olefinic bonds, indicating the consumption of double bonds. The yield of this reaction was $95 \%$.

Hydrolysis of the epoxidation product $\mathbf{2}$ provided a mixture of hydroxylated compounds (3). Infrared spectrum showed a more intense absorption band at $3399 \mathrm{~cm}^{-1}$ related to the new $\mathrm{O}-\mathrm{H}$ bonds. The infrared spectrum of 


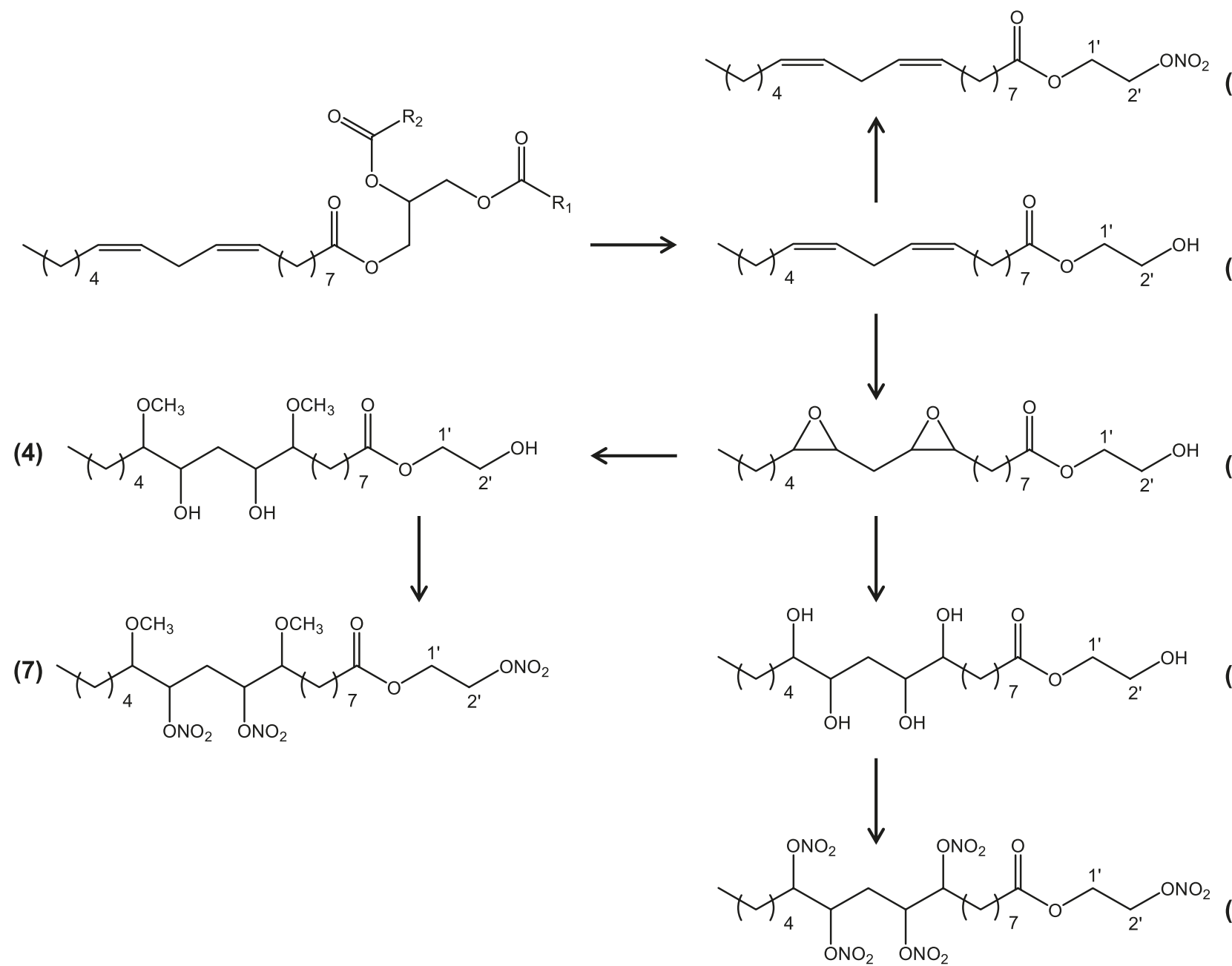

Figure 1. Synthetic route of the products from triacylglycerides. All chemical structures are represented by linoleic chain, which is the major hydrocarbon chain of soybean oil triacylglycerides.

the mixture of epoxides presented a less intense absorption band at $3435 \mathrm{~cm}^{-1}$ corresponding to the $\mathrm{O}-\mathrm{H}$ bond of ethylene glycol chain. ${ }^{13} \mathrm{C}$ NMR spectrum showed a new signal between 70-75 ppm related to the carbons bonded to hydroxyl groups. The signal at $53.4 \mathrm{ppm}$ was not observed. The yield of the hydrolysis product 3 was $93 \%$.

Solvolysis of the epoxidation product 2 was carried out with methanol using concentrated sulfuric acid at $70{ }^{\circ} \mathrm{C}$ for $12 \mathrm{~h}$. Infrared spectrum showed an increase in the intensity of the absorption bands in the region between $1198-1090 \mathrm{~cm}^{-1}$, related to asymmetrical axial deformation of $\mathrm{C}-\mathrm{O}-\mathrm{C}$ bonds. ${ }^{1} \mathrm{H}$ NMR spectrum presented a signal at $3.62 \mathrm{ppm}$ related to the hydrogens from the methoxy group, confirming the formation of product 4 . The yield of solvolysis was $59 \%$.

The hydroxylated esters $\mathbf{1}, \mathbf{3}$ and $\mathbf{4}$ reacted with fuming nitric acid in the presence of acetic anhydride and dichloromethane to obtain the organic nitrates. Infrared spectra of the nitrate products $\mathbf{5 , 6}$ and $\mathbf{7}$ showed intense absorption bands around 1640 and $1550 \mathrm{~cm}^{-1}$, related to axial asymmetrical deformation of the $\mathrm{NO}_{2}$ group. Absorption at $1280 \mathrm{~cm}^{-1}$ corresponds to the axial symmetrical deformation and a band at $857 \mathrm{~cm}^{-1}$ is related to the axial deformation of the $\pi$ bond $\mathrm{N}-\mathrm{O}$. The $\mathrm{O}-\mathrm{H}$ bonds absorption band was not observed. The presence of an intense absorption band around $1740 \mathrm{~cm}^{-1}$ is related to the axial deformation of $\mathrm{C}=\mathrm{O}$ bonds. $\mathrm{A}$ low intensity band was observed in the region of $760-690 \mathrm{~cm}^{-1}$ related to the angular deflection of the nitro group. The yields of the products of nitration are shown in Table 2.

Table 2. Yields of organic nitrates products

\begin{tabular}{lc}
\hline Product & Yield / \% \\
\hline Nitrates of soybean ethylene glycol esters (5) & 89 \\
Nitrates of soybean hydroxylated ethylene glycol esters (6) & 55 \\
Nitrates of soybean methoxylated ethylene glycol esters (7) & 85 \\
\hline
\end{tabular}

A second series of products was synthesized by esterification of linoleic acid, oleic acid and stearic acid 
(8)<smiles>CC(C)(C)/C=C\C/C=C\CCC(=O)OC[CH]CO</smiles>

(9)<smiles>CCCCCCCCCCCCC(C)(C)C(=O)OC[CH]CO</smiles>

(10)<smiles>CC(C)(C)CCCCCCC(=O)O[C]CO</smiles>

(11)<smiles>CC(C)(C)C=CCC=CCC(C)(C)C(=O)OC[CH]CO[N+](=O)[O-]</smiles>

(12)<smiles>CCCCCCC=CCCC(C)(C)C(=O)OC[CH]CO[N+](=O)[O-]</smiles>

(13)<smiles></smiles>

Figure 2. Structure of derivatives from linoleic acid (products $\mathbf{8}$ and 11), oleic acid (products 9 and 12) and stearic acid (products $\mathbf{1 0}$ and $\mathbf{1 3}$ ).

with ethylene glycol. The ethylene glycol esters 8,9 and 10 were then converted in the respective nitrates 11, 12 and 13. The structures of the products can be seen in Figure 2. The ${ }^{1} \mathrm{H}$ NMR, ${ }^{13} \mathrm{C}$ NMR and IR spectra of ethylene glycol linoleate (8), ethylene glycol oleate (9) and ethylene glycol stearate (10) showed the same characteristic signals observed on the correspondent spectra of soybean ethylene glycol esters (1). However, the ${ }^{1} \mathrm{H}$ and ${ }^{13} \mathrm{C}$ NMR spectra of ethylene glycol stearate (10) do not present signals in the region of 5.0-5.5 and 120-130 ppm, respectively, related to hydrogens and carbons of the double bonds. And the infrared spectrum of ethylene glycol stearate (10) does not present the band at $3009 \mathrm{~cm}^{-1}$ because the hydrocarbon chain has no double bond. IR spectra of the nitrates 11, 12 and 13 showed absorption bands characteristic of the presence of $\mathrm{NO}_{2}$ group. The yields of the products $8,9, \mathbf{1 0}$, 11, 12 and $\mathbf{1 3}$ are shown in Table 3.

Table 3. Yields of the esterification and nitration products from fatty acids

\begin{tabular}{lc}
\hline Product & Yield / \% \\
\hline Ethylene glycol linoleate (8) & 99 \\
Ethylene glycol oleate (9) & 96 \\
Ethylene glycol stearate (10) & 82 \\
Nitrate of ethylene glycol linoleate (11) & 97 \\
Nitrate of ethylene glycol oleate (12) & 96 \\
Nitrate of ethylene glycol stearate (13) & 70 \\
\hline
\end{tabular}

A third series of products was prepared by the transesterification of castor oil and jatropha oil with ethylene glycol to the respective mixture of ethylene glycol esters 14 and $\mathbf{1 5}$, followed by nitration to obtain the nitrates $\mathbf{1 6}$ and 17. Finally, soybean oil was transesterified with glycerol to obtain the product $\mathbf{1 8}$, which was then converted in the correspondent nitrated product 19. Figure 3 illustrates the structures of monolinolein and its nitrate derivative, major constituents of products $\mathbf{1 8}$ and $\mathbf{1 9}$, respectively. NMR and IR spectra confirmed the synthesis of the products. Table 4 shows the yields of the vegetable oils derivatives.

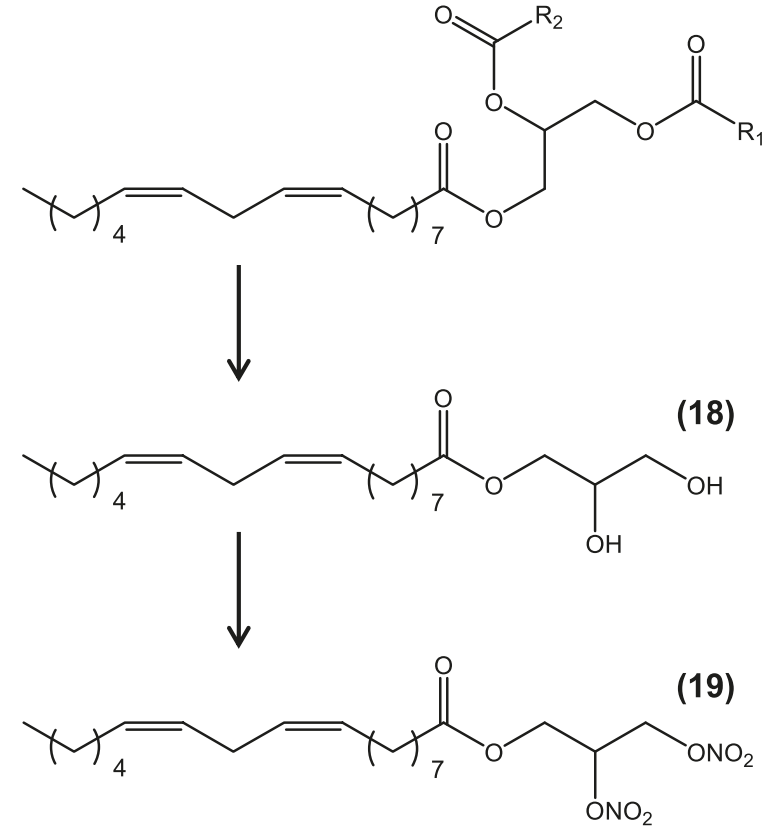

Figure 3. Synthetic route of the products $\mathbf{1 8}$ and $\mathbf{1 9}$ from soybean oil. The structures of the triacylglyceride and the products are exemplified by linoleic chain.

Table 4. Yields of the esterification and nitration products from the vegetable oils

\begin{tabular}{lc}
\hline Product & Yield / \% \\
\hline Jatropha ethylene glycol esters (14) & 60 \\
Castor ethylene glycol esters (15) & 84 \\
Nitrates of jatropha ethylene glycol esters (16) & 95 \\
Nitrates of castor ethylene glycol esters (17) & 82 \\
Soybean glycerol esters (18) & 62 \\
Nitrates of soybean glycerol esters (19) & 70 \\
\hline
\end{tabular}

Antimicrobial activity tests of soybean derived additives (products 2, 3, 5, 6 and 7)

Initially, the synthesized products $\mathbf{2 , 3 , 5 , 6}$ and $\mathbf{7}$ were tested for biocide activity. An inhibition zone of $10 \mathrm{~mm}$ was conventionally adopted as the threshold limit value 
to characterize a biocide activity. The results of the agar diffusion tests with fungi showed that the products $\mathbf{5}$ and 6 present fungicidal activity since the formation of an inhibition halo greater than $10 \mathrm{~mm}$ was observed in the presence of these products. None of the products tested inhibited the growth of bacteria.

The product $\mathbf{5}$, a mixture of nitrates of soybean ethylene glycol esters, was active against the two species of filamentous fungi tested. For Aspergillus fumigatus, the agar diffusion test showed an average inhibitory zone of $22.33 \mathrm{~mm}$ with the application of biodiesel containing $0.75 \% \mathrm{v} / \mathrm{v}$ of product 5 . An inhibitory zone of $28.00 \mathrm{~mm}$ was observed when the product $\mathbf{5}$ was directly deposited in the reservoir. For Aspergillus niger, the product 5 presented activity in a concentration of $1.0 \% \mathrm{v} / \mathrm{v}$ in biodiesel reaching an average inhibition zone of $21.33 \mathrm{~mm}$, which slightly increased with the concentration. The test with pure product 5 exhibited an average inhibition zone of $26.00 \mathrm{~mm}$ for A. niger.

The antimicrobial susceptibility test was performed for the products that showed positive biocide activity in the agar diffusion test. Despite the good activity in the agar diffusion test for the genus Aspergillus, the MIC values for the product 5 were higher than $500 \mu \mathrm{g} \mathrm{mL}^{-1}$. The strain was considered susceptible to the antimicrobial candidate when a MIC lower than $256 \mu \mathrm{g} \mathrm{mL}^{-1}$ was observed. For Candida albicans, there was activity in the agar test only with the pure product $\mathbf{5}$. In the susceptibility test, however, the product 5 had a MIC of $83.5 \mu \mathrm{g} \mathrm{mL} \mathrm{m}^{-1}$. The fungicidal activity of the product $\mathbf{5}$ can be seen in Table 5 .

Product $\mathbf{6}$ showed also activity for the genus Aspergillus. The pure product 6 showed activity for A. niger and A. fumigatus with an average inhibitory zone of 25.00 and $13.66 \mathrm{~mm}$, respectively. The fungicidal activity of product 6 is possible to be observed until its addition of $1 \% \mathrm{v} / \mathrm{v}$ in biodiesel. In this concentration, the average inhibition zone was 22.33 and $10.33 \mathrm{~mm}$ for A. niger and A. fumigatus, respectively. These values can be observed in Table 6 . The MIC values for the product 6 followed the same tendency of the product 5 , being higher than $600 \mu \mathrm{gL}^{-1}$.

\section{Antimicrobial activity tests of products 11, 12 and 13}

From the first set of tests, only products $\mathbf{5}$ and $\mathbf{6}$ showed fungicidal activity. These products are derived from soybean oil and, consequently, their major constituents are the nitrates of linoleic and oleic esters. In order to investigate the effect of these constituents individually on the biocide activity, the respective nitrates $\mathbf{1 1}$ and $\mathbf{1 2}$ were synthesized from their pure fatty acids. Nitrate of ethylene glycol stearate (13) was also tested in order to evaluate if the presence of double bond in the hydrocarbon chain of the product contributes or not to the antimicrobial activity.

Product 11, nitrate of ethylene glycol linoleate, showed activity against $A$. niger and $A$. fumigatus with an average inhibitory zone of $13.00 \mathrm{~mm}$ for the two Aspergillus

Table 5. Diameter of the inhibition zone using product $\mathbf{5}$ as additive

\begin{tabular}{|c|c|c|c|c|c|c|c|}
\hline \multirow{3}{*}{ Fungus } & \multicolumn{7}{|c|}{ Inhibition zone diameter / $\mathrm{mm}$} \\
\hline & \multicolumn{6}{|c|}{ Concentration of the product 5 in biodiesel (v/v) } & \multirow{2}{*}{$\begin{array}{l}\text { Pure product } \\
\quad(100 \%)\end{array}$} \\
\hline & $0.25 \%$ & $0.50 \%$ & $0.75 \%$ & $1.0 \%$ & $25 \%$ & $50 \%$ & \\
\hline C. albicans & - & - & - & - & - & - & 15.66 \\
\hline A. niger & - & - & - & 21.33 & 22.50 & 23.00 & 26.00 \\
\hline A. fumigatus & - & - & 22.33 & 22.30 & 23.00 & 25.33 & 28.00 \\
\hline S. cerevisiae & - & - & - & - & - & - & - \\
\hline
\end{tabular}

-: no inhibition observed.

Table 6. Diameter of the inhibition zone using product $\mathbf{6}$ as additive

\begin{tabular}{|c|c|c|c|c|c|c|c|}
\hline \multirow{3}{*}{ Fungus } & \multicolumn{7}{|c|}{ Inhibition zone diameter / mm } \\
\hline & \multicolumn{6}{|c|}{ Concentration of the product 6 in biodiesel (v/v) } & \multirow{2}{*}{$\begin{array}{l}\text { Pure product } \\
\quad(100 \%)\end{array}$} \\
\hline & $0.25 \%$ & $0.50 \%$ & $0.75 \%$ & $1.0 \%$ & $25 \%$ & $50 \%$ & \\
\hline C. albicans & - & - & - & - & - & - & - \\
\hline A. niger & - & - & - & 22.33 & 23.00 & 25.00 & 25.00 \\
\hline A. fumigatus & - & - & - & 10.33 & 10.00 & 11.00 & 13.66 \\
\hline S. cerevisiae & - & - & - & - & - & - & - \\
\hline
\end{tabular}


Table 7. Diameter of the inhibition zone using product $\mathbf{1 9}$ as additive

\begin{tabular}{|c|c|c|c|c|c|c|c|}
\hline \multirow{3}{*}{ Fungus } & \multicolumn{7}{|c|}{ Inhibition zone diameter / $\mathrm{mm}$} \\
\hline & \multicolumn{6}{|c|}{ Concentration of the product 19 in biodiesel (v/v) } & \multirow{2}{*}{$\begin{array}{l}\text { Pure product } \\
\quad(100 \%)\end{array}$} \\
\hline & $0.25 \%$ & $0.50 \%$ & $0.75 \%$ & $1.0 \%$ & $25 \%$ & $50 \%$ & \\
\hline C. albicans & - & - & - & - & - & - & - \\
\hline A. niger & - & - & - & 21.33 & 21.50 & 23.00 & 23.50 \\
\hline A. fumigatus & - & - & - & 12.50 & 13.33 & 15.00 & 15.00 \\
\hline S. cerevisiae & - & - & - & - & - & - & - \\
\hline
\end{tabular}

-: no inhibition observed.

species. This result was observed using $25 \% \mathrm{v} / \mathrm{v}$ of product $\mathbf{1 1}$ in biodiesel for $A$. fumigatus and $50 \% \mathrm{v} / \mathrm{v}$ for A. niger. The agar diffusion test with product $\mathbf{1 1}$ resulted in a lower inhibition zone when compared to that observed with product 5. However, in the susceptibility test, the nitrate of ethylene glycol linoleate (11) had an MIC of $83.5 \mu \mathrm{g} \mathrm{mL}^{-1}$ against $A$. fumigatus, while the MIC value for the mixture of nitrates of soybean ethylene glycol esters (5) was higher than $500 \mu \mathrm{g} \mathrm{mL}^{-1}$.

Products 12 and 13 showed no fungicidal activity. This result suggests that the two double bonds in the hydrocarbon chain also affect in some way the biocide activity.

\section{Antimicrobial activity tests of products 16, 17 and 19}

Nitrates synthesized from jatropha and castor oils, products $\mathbf{1 6}$ and $\mathbf{1 7}$, were also evaluated and showed no potential fungicidal activity as observed for the product $\mathbf{5}$ derived from soybean oil. This result corroborates some previous observations. Castor oil has approximately $90 \%$ of ricinoleic acid in its composition. Nitration of the product $\mathbf{1 5}$ also leads to the conversion of the hydroxyl at C-9 position to the nitrate group. The presence of a nitrate group associated with a double bond in the hydrocarbon chain was not relevant to promote the biocide activity. Jatropha oil, on the other hand, consists of approximately $50 \%$ oleic acid and $30 \%$ linoleic acid. In the agar diffusion test with the product $\mathbf{1 6}$ there was also no inhibition of microorganism growth. This result confirms previous observations that nitrate of ethylene glycol oleate has no fungicidal action. In addition, the presence of nitrate of ethylene glycol linoleate in a lower concentration did not inhibit the growth of fungi.

Finally, soybean oil was transesterified with glycerol and the monoacylglycerides mixture (18) was then converted to the mixture of nitrates (19). Product 19, as well as product $\mathbf{5}$, presented biocide activity against Aspergillus genus in a concentration of $1 \% \mathrm{v} / \mathrm{v}$ in biodiesel. Inhibition zones were 21.33 and $12.50 \mathrm{~mm}$ for $A$. niger and
A. fumigatus, respectively. This result strongly indicates that the fungicidal activity is related to the presence of the two double bonds in the hydrocarbon chain. The values of the inhibition zone observed in the presence of the product $\mathbf{1 9}$ are shown in Table 7.

It is important to mention that all the inhibition results of the agar diffusion tests pointed to a biocidal action since there was no growth of microorganism throughout the halo region. This observation eliminates the possibility of being only a biostatic action.

Evaluation of nitrated products 5, 6, 7 and 19 as cetane number improver

The products were tested in $0.2 \% \mathrm{v} / \mathrm{v}$ in biodiesel/ diesel blend containing 7\% v/v of soybean biodiesel (B7). The results of cetane number measurement were shown in Table 8.

Table 8. Cetane number of organic nitrates

\begin{tabular}{lc}
\hline Product & Cetane number \\
\hline B7 & 53.41 \\
$\mathbf{7}$ & 56.82 \\
$\mathbf{6}$ & 55.18 \\
$\mathbf{5}$ & 52.87 \\
$\mathbf{1 9}$ & 52.52 \\
\hline
\end{tabular}

The $\mathrm{CN}$ of $\mathrm{B} 7$, which is the reference, showed the value of 53.41. The products $\mathbf{6}$ and $\mathbf{7}$ showed shorter ignition delay, improving the $\mathrm{CN}$. On the other hand, derivatives 5 and 19 showed decreased $\mathrm{CN}$.

The improvement of $\mathrm{CN}$ by addition of product $7 \mathrm{can}$ be justified by the presence of methoxy groups in the middle of the hydrocarbon chains of the product. The oxygen, which is a very electronegative atom, distorts the electron density and increases susceptibility to breakage of carbon-oxygen bond, facilitating combustion reaction. Additionally, 
nitrate groups have large contribution to the improvement in cetane number. So, the presence of nitrate groups in the hydrocarbon chain also justified the $\mathrm{CN}$ improvement promoted by products 6 and 7 .

In contrast, products $\mathbf{5}$ and $\mathbf{1 9}$ have nitrate group only in the alkoxy moiety. The absence of this group in the middle of the hydrocarbon chain could just not change the $\mathrm{CN}$ value of B7. However, the presence of double bond in the hydrocarbon chain requires more energy to form combustion products, leading to increased ignition delay and reduced $\mathrm{CN}$.

\section{Conclusions}

The development of biocides for biodiesel is necessary and strategic not only in terms of preserving the quality of the fuel, but also the economic amount involved due to the worldwide growing demand for biodiesel. The purpose of this work was to synthesize biocide candidates which were chemically compatible to biodiesel using simple and low cost chemical transformations. None of the products tested inhibited the growth of bacteria. However, four nitrated derivatives were active against species of Aspergillus, fungus commonly found in biodiesel/diesel blends. Considering the chemical structure of the tested products, the results indicated that the fungicidal activity can be related to the nitration of the hydroxyl group in the alkoxy moiety of the esters, preserving the double bonds in the middle of the hydrocarbon chain. The nitrated derivatives were also evaluated as cetane number improvers. Regarding this physical-chemical property, the insertion of methoxyl and nitrate groups in the middle of the hydrocarbon chain increased the ignition quality of B7 biodiesel/diesel blend.

The results showed that potential additives can be revealed from chemical modifications in the same raw material used for biodiesel production. It is expected that this work motivates the investigation of new triacylglyceride derivatives in order to find commercial promising additives.

\section{Supplementary Information}

Supplementary information (spectroscopic data, ${ }^{1} \mathrm{H}$ NMR, ${ }^{13} \mathrm{C}$ NMR and IR spectra) is available free of charge at http://jbcs.sbq.org.br as PDF file.

\section{Acknowledgments}

The authors would like to thank CNPq, CAPES (Brazilian Research Councils), FAPDF, FAPERJ (Rio de Janeiro State Research Sponsor Foundation, grant number
E-26/112.190/2012) and ANP (Brazilian National Agency of Petroleum, Natural Gas and Biofuels) for financial support. P. A. Z. S. thanks CNPq for research fellowship.

\section{References}

1. Schleicher, T.; Werkmeister, R.; Russ, W.; Meyer-Pittroff, R.; Bioresour. Technol. 2009, 100, 724.

2. Carvalho Jr., J. A.; Lacava, P. T.; Emissões em Processos de Combustão; Editora UNESP: São Paulo, 2003.

3. Pousa, G. P. A. G.; Santos, A. L. F.; Suarez, P. A. Z.; Energy Policy 2007, 35, 5393.

4. Helwani, Z.; Othman, M. R.; Aziz, N.; Fernando, W. J. N.; Kim, J.; Fuel Process. Technol. 2009, 90, 1502.

5. Pinho, D. M. M.; Santos Jr., V. O.; Oliveira, M. C. S.; Silva, M. T.; Piza, P. G. T.; Pinto, A. C.; Rezende, M. J. C.; Suarez, P. A. Z.; Fuel 2014, 136, 136.

6. Passman, F. J.; Natl. Pet. News 1999, 91, 20.

7. Bento, M.; Beech, I. B.; Gaylarde, C. C.; Englert, G. E.; World J. Microbiol. Biotechnol. 2005, 21, 135.

8. Zimmer, A.; Cazarolli, J.; Teixeira, R. M.; Viscardi, S. L. C.; Cavalcanti, E. S. H.; Gerbase, A. E.; Ferrão, M. F.; Piatnicki, C. M. S.; Bento, F. M.; Fuel 2013, 112, 153.

9. Gaylarde, C. C.; Bento, F. M.; Kelley, J.; Rev. Microbiol. 1999, 30,1 .

10. Ghazali, F. M.; Rahman, R. N. Z. A.; Salleh, A. B.; Basri, M.; Int. Biodeterior. Biodegrad. 2004, 54, 61.

11. Passman, F. J.; Int. Biodeterior. Biodegrad. 2013, 81, 88.

12. Jakeria, M. R.; Fazal, M. A.; Haseeb, A. S. M. A.; Renewable Sustainable Energy Rev. 2014, 30, 154.

13. Bücker, F.; Barbosa, C. S.; Quadros, P. D.; Bueno, M. K.; Fiori, P.; Huang, C. t.; Frazzon, A. P. G.; Ferrão, M. F.; Camargo, F. A. O.; Bento, F. M.; Int. Biodeterior. Biodegrad. 2014, 95, 346.

14. Cazarolli, J. C.; Guzatto, R.; Samios, D.; Peralba, M. C. R.; Cavalcanti, E. H. S.; Bento, F. M.; Int. Biodeterior. Biodegrad. 2014, 95, 364.

15. Zimmer, A. R.; Oliboni, A.; Viscardi, S. L. C.; Teixeira, R. M.; Ferrão, M. F.; Bento, F. M.; Biofuel Res. J. 2017, 14, 627.

16. Agência Nacional do Petróleo Gás Natural e Biocombustíveis (ANP), Resolution ANP No. 30; Diário Oficial da União, Brasília, 2016. Available at http://legislacao.anp.gov.br/?path=legislacaoanp/resol-anp/2016/junho\&item=ranp-30--2016, accessed in July 2018.

17. Heyhood, J. B.; Internal Combustion Engine Fundamentals; McGraw-Hill: New York, 1988.

18. Saldana, D. A.; Starck, L.; Mougin, P.; Rousseau, B.; Pidol, L.; Jeuland, N.; Creton, B.; Energy Fuels 2011, 25, 3900.

19. Ullman, T. L.; Mason, R. L.; Montalvo, D. A.; SAE [Tech. Pap.] 1990, 902171.

20. Nandi, M. K.; Jacobs, D. C.; Liotta, F. J.; Kesling, H. S.; SAE [Tech. Pap.] 1994, 942019. 
21. Pundir, B. P.; Singal, S. K.; Gondal, A. K.; SAE [Tech. Pap.] 1994, 942020.

22. Schwab, S. D.; Guinther, G. H.; Henly, T. J.; Miller, K. T.; SAE [Tech. Pap.] 1999, 1999-01-1478.

23. Szklo, A. S.; Uller, V. C.; Fundamentos do Refino de Petróleo: Tecnologia e Economia, $3^{\mathrm{a}}$ ed.; Interciência: Rio de Janeiro, 2008.

24. Akasaka, Y.; Sakurai, Y.; SAE [Tech. Pap.] 1994, 942023.

25. Soares Jr., L. C. S.; Ferreira, V. P.; da Silva, J. A. M.; Torres, E. A.; Pepe, I. M.; J. Braz. Soc. Mech. Sci. Eng. 2018, 40, 79.

26. Suppes, G. J.; Rui, Y.; Rome, A. C.; Chen, Z.; Ind. Eng. Chem. Res. 1997, 36, 4397.

27. Fabri, J.; Dabelstein, W.; Reglitzky, A. In Ullmann's Encyclopedia of Industrial Chemistry, vol. A16; Wiley-VCH: Weinheim, 1990, p. 719-753.

28. Ramalho, H. F.; Ferreira, K. M. C.; Machado, P. M. A.; Silva, T. B.; Rangel, E. T.; Prauchner, M. J.; Suarez, P. A. Z.; J. Braz. Chem. Soc. 2015, 27, 321.

29. Suppes, G. J.; Chen, Z.; Rui, Y.; Mason, M.; Heppert, J. A.; Fuel 1999, 78, 73.

30. Suppes, G. J.; Goff, M.; Burkhart, M. L.; Bockwinkel, K.; Mason, M. H.; Botts, J. B.; Heppert, J. A.; Energy Fuels 2001, $15,151$.

31. Suppes, G. J.; Dasari, M. A.; Ind. Eng. Chem. Res. 2003, 42, 5042.

32. Canoira, L.; Alcántara, R.; Torcal, S.; Tsiouvaras, N.; Lois, E.; Korres, D. M.; Fuel 2007, 86, 965.
33. Gelbard, G.; Brès, O.; Vargas, R. M.; Vielfaure, F.; Schuchardt, U. F.; J. Am. Oil Chem. Soc. 1995, 72, 1239.

34. Bauer, A. W.; Kirby, W. M.; Sherris, J. C.; Turck, M.; Am. J. Clin. Pathol. 1966, 45, 493.

35. Bento, F. M.; Gaylarde, C. C.; Rev. Microbiol. 1996, 27, 192.

36. FIOCRUZ-INCQS; Reference Collection of Microorganisms in Health Surveillance - CMRVS; FIOCRUZ: Rio de Janeiro, 2017.

37. Clinical and Laboratory Standards Institute (CLSI); Performance Standards for Antimicrobial Susceptibility Testing; Twenty-First Informational Supplement; CLSI: Wayne, PA, 2011.

38. Bâati, L.; Fabre-Gea, C.; Auriol, D.; Blanc, P. J.; Int. J. Food Microbiol. 2000, 59, 241.

39. Fahy, G. M.; Cryobiology 2010, 60, S45.

40. National Committee for Clinical Laboratory Standards (NCCLS); Performance Standards for Antimicrobial Susceptibility Testing; Information Supplement 15 $5^{\text {th }}$ M100-S15; NCCLS: Wayne, PA, 2005.

41. ASTM D6890-16e2: Standard Test Method for Determination of Ignition Delay and Derived Cetane Number (DCN) of Diesel Fuel Oils by Combustion in a Constant Volume Chamber; ASTM International, West Conshohocken, PA, 2016.

Submitted: April 12, 2018

Published online: July 20, 2018 